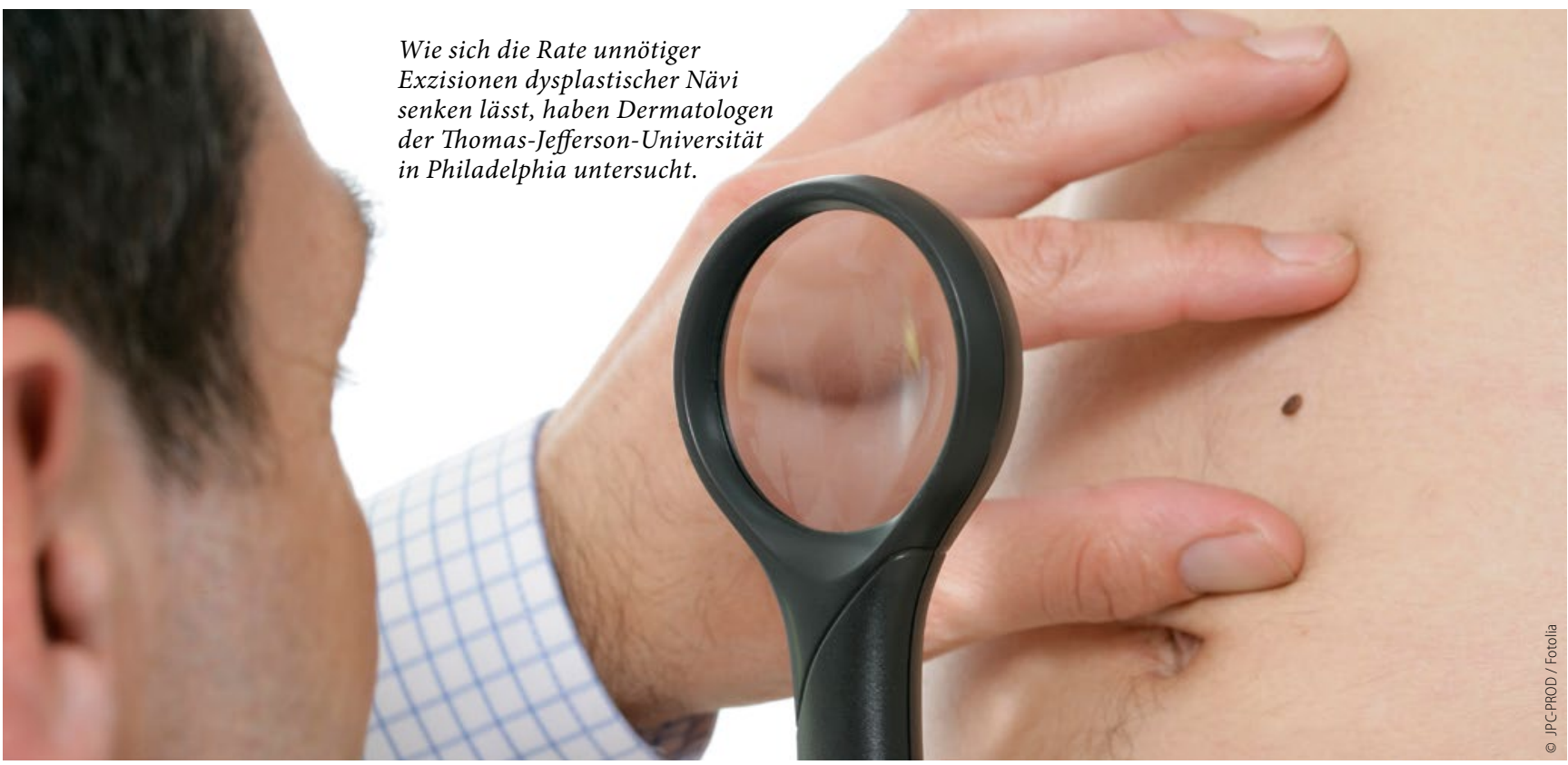

\title{
US-Dermatologen werfen Grading-System über Bord
}

\begin{abstract}
Die Einteilung dysplastischer Nävi nach dem Grad der Dysplasie erhöht laut einer Studie von US-amerikanischen Hautärzten unnötig die (Re-)Exzisionsrate. Sie raten, solche Male nur zu entfernen, wenn Zweifel an der Diagnose bestehen.
\end{abstract}

Dem Grading biopsierter dysplastischer Nävi liegt die Vorstellung zugrunde, wonach diese Male Übergangsformen zwischen benignen und malignen Veränderungen darstellen. Demgemäß werden sie entsprechend dem histopathologischen Bild, das sich unter anderem am Muster melanozytärer Atypien orientiert, in leicht, mäßig oder schwer dysplastisch eingeteilt.

\section{Viele Exzisionen, wenig Ertrag}

Dies führt zu Exzisionsraten von teilweise mehr als $50 \%$, wobei den Dermatologen dabei nur selten ein Melanom ins Netz geht. Eine Strategie, solcherart überflüssige Exzisionen zu vermeiden, besteht darin, die dysplastischen Nävi nicht nach Graden einzuteilen, sondern danach, ob eindeutig ein wie schwer auch immer dysplastischer Nävus vorliegt oder ob daran aufgrund untypischer Merkmale Zweifel bestehen.

Hautärzte der Thomas-Jefferson-Universität in Philadelphia haben die Effizienz des zweiten Ansatzes in einer Studie geprüft. Daniel Lozeau und Kollegen verwendeten dafür die histopathologischen Daten von mehr als 17.000 entfernten junktionalen oder Compound-Nävi. 50,8\% wurden als dysplastisch etikettiert, wobei für 11,1\% dieser Male aufgrund diagnostischer Unsicherheit die Re-Exzision empfohlen wurde.

\section{Geringe Irrtumsrate}

$79,8 \%$ der fraglichen dysplastischen Nävi wurden schließlich tatsächlich exzidiert und anschließend ans dermatopathologische Labor zurückgeschickt. In $81,2 \%$ dieser Proben war kein melanozytärer Tumor mehr feststellbar. Eine identifizierbare benigne Komponente lag in 16,1 \% der Fälle vor. Melanozytäre Läsionen unklarer Dignität waren mit $0,8 \%$ vertreten, und bei $2 \%$ lautete die Diagnose auf Melanom - keines dicker als $0,45 \mathrm{~mm}$ und in vier von fünf Fällen noch in situ. Die Irrtumsrate - gemessen als Revision der Erstdiagnose - lag somit bei $0,2 \%$.

„Verglichen mit den bisher dokumentierten Exzisionsraten werden dysplastische Nävi nach Verzicht auf ein Grading seltener ausgeschnitten“, schreiben Lozeau und seine Mitarbeiter. Die ursprüngliche Diagnose müsse dennoch nur selten berichtigt werden. Die Studie scheint zudem zu bestätigen, dass es sich bei dysplastischen Nävi weniger um intermediäre Läsionen zwischen benigne und maligne handelt. Ihre Rolle wäre vielmehr die eines Markers für das Melanomrisiko. Sofern solche Nävi aber keine Vorläufer zu Melanomen darstellen, entfiele auch der Sinn ihres Gradings.

Dr. Robert Bublak 